\title{
Vigilance of tap water quality: what is the potential for relying on individuals as alarm raisers?
}

\author{
C. Heitz \& P. Ward-Perkins \\ GESTE-ENGEES/IRSTEA, France
}

\begin{abstract}
As part of a bi-national research project, 600 tap water users living in three European cities (two in France, one in Germany) have been surveyed by telephone in order to explore laypersons' (i.e. non-specialists) expectations of drinking water quality and how they might respond in the event of a sudden crisis related to tap water quality. Our survey as a whole explores: water consumption behaviour, knowledge of the water distribution system, perceptions of water quality and its risks, legitimacy of experts to inform the public about water quality, and the capacity of consumers to react rapidly and communicate effectively (i.e. to "raise the alarm") in the event of an unexpected crisis. This paper mainly focuses on the latter of these aspects. Results of the survey firstly reveal a fairly low level of knowledge of the public water distribution system and its stakeholders. Results also suggest a common definition of "quality water", that includes being free of colour, smell, taste, chlorine and limestone but should contain minerals. Results finally reveal that water users view favourably the idea of the lay public participating in water quality vigilance but in practice it would appear that, in the current configuration, water users would make poor "alarm raisers". To develop greater consumer vigilance, in the interests of public safety, this study suggests a need for greater awareness of risks relating to drinking water, and thus a need for more effective communication between the water supplier and tap water users.
\end{abstract} Keywords: drinking water quality, survey, tap water quality perception, technology and vigilance, individual behaviour. 


\section{Introduction}

Since Beck's works on society and risks [1], it has been argued in the social sciences that we live in a risk society where new technology can bring us great advances in safety and comfort, but can also generate new risks and uncertainties. The distribution of drinking water is directly concerned by this kind of consideration: the consumption of tap water is mostly safe but the technology developed to bring water to its users might also generate new risks and uncertainties. Since 1960s, many studies have been done to understand how individuals perceive tap water and its potential risks [2-4].

From a technical angle, some of these risks and uncertainties have already been identified. Previous studies argue that the complexity of the water distribution network is what makes it particularly vulnerable to contaminations because of degradation $[5,6]$ or potential attacks $[7,8]$. On the subject of intentional contaminations, Salzman [8] states that although nowadays a very rare and unlikely event, drinking water has made throughout history a very attractive target for attacks because of the particularly powerful impact they could have.

Our study takes place as part of Project "SMaRT-OnLine WDN", a FrenchGerman research project in which researches are focused on the development of a system for real-time management of drinking water distribution networks. The project aims to make possible real-time detections of sudden contaminations of drinking water, in order to facilitate an immediate response to the threat. Technical issues such as the development of alarm controls, or software allowing the modelling of potential contaminations in the network $[9,10]$ and social aspects are questioned in this project. This social analysis deals with the analysis of risk management procedures in the distribution of drinking water, and the influence these might have on individuals' behaviour in case of a disaster. Three sites have served as study ground: Strasbourg (East of France), 3 medium sized towns in Paris-Ile de France (France) and Berlin (Germany). In this paper, we address specifically the question of what role water users can play in monitoring tap water quality. Following discussions with experts from the project, it was acknowledged that water suppliers relied on users' feedback to identify sudden losses of water quality. Consequently in our research, two main hypotheses were controlled: (H1) The water users are able to identify a threat on the water quality; (H2) The water users are able to inform other individuals or the stakeholders in case of a threat. It should be noted that although results point to significant differences between sites, explanations of these are beyond the scope of this specific paper, notably those relating to cross-national differences.

This paper will be presenting our study through 4 sections: we will firstly present elements of literature and concepts which were used to build the survey and interpret results, we will secondly present the main elements of our methodology, thirdly we will present our main results, and lastly we will discuss our results and highlight some interesting outcomes. 


\section{Literature and key concepts in use: trust and alarm raising to understand individuals' behaviour}

In order to study individual behaviour, two important concepts have been explored and are here presented: trust and alarm raisers.

\subsection{Trust}

According to Cvetkovich [11], trust is central to establishing and maintaining political legitimacy in hazard management. But how is trust to be understood? Lewis and Weigert [12] define trust through 3 dimensions: "cognition", "affective component" and "behavioral component". They distinguish trust from confidence and legitimacy and define some indicators that allow us to assess the level of trust in risk regulation $[13,14]$. Cvetkovitch [11] define 4 indicators: honesty, fairness, neutrality, and impartiality of the trustee. By the study of these indicators, they can measure the level of trust, which can be useful to decrease the complexity of a situation. It has also been shown that trust is particularly important for fostering collaborations and that a strong relation between trust and perception can be established [15-19]. Furthermore, trust and public participation are also related: when people trust in their stakeholders' decisions, they accept to collaborate to implement risk management policies [13, 20-22]. Therefore communication and information campaigns can benefit strongly from high levels of trust.

The concept of trust is frequently used in risk management [23, 24] and even though the issues are not entirely the same in situations of a hazard management and a contamination analysis, 4 main issues have been identified. Our survey thus aims to: (i) identify the trustee (from the individual point of view) involved in drinking water supply; (ii) understand the level of trust/distrust of the trustee; (iii) identify, in case of distrust, the main issues revealed by the individuals; (iv) question the role of responsibility/legitimacy of some stakeholders in trust.

\subsection{Alarm raisers}

The concept of "alarm raisers" was first coined by Chateauraynaud and Torny [25] to describe individuals or groups which brought to public attention previously unknown or underestimated matters of public safety. Why is it interesting to use the concept of "alarm raisers"? Firstly, it encourages us to understand to what extent people question the quality of water in case of a sanitary problem. Secondly, it encourages us to identify which stakeholders are held responsible to prevent such crises as well as which authorities water users will first alert. That is to say, by interrogating the individuals we can identify the authorities which are considered legitimate to the water users and also define the alarm raiser. This analysis will allow us to implement a common frame of action by increasing potential level of mobilisation of all the stakeholders, including water users, in a crisis situation. Using the concept of alarm raisers also encourages us to assess the importance of "time" in the management of a risk related to drinking water. Chateauraynaud and Torny [25] identify 3 parameters to understand the "alarm 
time" and the "mobilisation time": the level of predictability, the degree of intentionality and the degree of reversibility of the disaster. By assessing these parameters in our survey, we will be able to define the alert management system perceived by both the stakeholders and the population.

When using the concept of alarm raisers, the main questions asked are: why do people raise an alarm and when are they most likely to do so? From this reflection, the study gives itself 5 objectives: (i) to understand the way water users perceive a specific good: drinking water; (ii) to question the way water users could become "whistle-blowers"; (iii) to know what kind of precursory signs could be significant for water users; (iv) to understand what kind of perceptual faculties are mobilised by water users before they alert public authorities; (v) to identify authorities which stakeholders water users consider legitimate to protect them from tap water contaminations.

\section{Methodology: questionnaire-based surveys and sampling frame}

To better understand the role that water users could play in the event of sudden and unexpected contamination of tap water, we developed a questionnaire based survey (based on qualitative interviews with inhabitants of all three sites concerned). Our survey mobilised respondents from all three sites covered by the project: Strasbourg, Paris-Ile de France and Berlin. We gathered a total of 602 answers, amounting to roughly 200 answers per site. All three sites correspond to densely populated and urbanised areas under the responsibility of three different water suppliers. The survey was passed by telephone during the month of May 2014. The average call lasted 22 minutes. Applying quota methodology, telephone surveyors were instructed to obtain a representative sample in terms of age, gender and socio-economic group. It is important to mention that the last criterion proved to be more difficult to fulfil in the German site due to lack of precise data available on that area.

The survey covers six sections: (i) description of the individual; (ii) general behaviour and attitudes towards the environment and water; (iii) knowledge of drinking water management and its stakeholders; (iv) trust and legitimacy of stakeholders of drinking water management; (v) perception of drinking water security; and (vi) beliefs and values concerning the future of drinking water security.

More specifically, exploring the idea of participatory vigilance (meaning that individuals could play an active role in the surveillance of water quality), the survey interrogated two key behaviours individuals should adopt in order to minimise the impact of a contamination. Individuals should be able to firstly identify a sudden loss of water quality, and secondly communicate as quickly as possible the noticed loss of quality to relevant stakeholders, i.e. local authorities and the water suppliers. 


\section{Results: from individuals' ability to prevent in case of a risk to their behaviours?}

\subsection{Description of sample}

The population in the three sites is well-balanced in terms of gender (male: $15 \%$; $15 \%$ and $16 \%$ respectively in Strasbourg, Paris-Ile de France and Berlin; female: $19 \% ; 18 \%$ and $17 \%$ respectively in Strasbourg, Paris-Ile de France and Berlin) and age, with a slight tendency towards an older population. But cross-comparisons with local statistics inform us that the sample is representative. In terms of types of households, the generally high apartment-to-house ratio (92:8\% in Strasbourg, $70: 30 \%$ in Paris-Ile de France and 73:27\% in Berlin) also confirms that we are dealing with a predominantly urban population. Finally, it can be noted that the Berlin site tends to demarcate itself from the other two sites by including a slightly less family focused population ( 0.15 children per household in Berlin as opposed to 0.43 in Strasbourg and 0.63 in Paris-Ile de France).

\subsection{Predisposition of individuals to identify a sudden loss of water quality}

\subsubsection{Criterion 1: Individual's perceived likeliness of water quality degradation}

In order to understand if a sudden loss of water quality might be identified, it can firstly be helpful to consider how likely such a change is believed to be.

Figure 1 makes apparent that there are strong similarities between the two French sites which equally significantly distinguish themselves from the German site: indeed only $13 \%$ believe sudden quality loss to be quite or very likely in the Berlin site as opposed to $39 \%$ and $34 \%$ in the Strasbourg and Paris-Ile de France sites. On the whole, figure 1 reveals to us that a sudden loss of water quality is generally considered unlikely. If we accept the assumption that an individual is more likely to detect an element which he/she expects (see confirmation bias [26]), then it follows that an individual expecting a sudden loss of water quality would in a real-life crisis situation be more likely to identify the contamination.

\subsubsection{Criterion 2: Water consumption behaviour of individuals}

One second aspect to consider is whether individuals drink tap or bottled water at home. From our results, we know that respectively 39\%, 37\% and 30\% of individuals in Strasbourg, Paris-Ile de France and Berlin practically never drink tap water at home, and thus these individuals are particularly unlikely to notice (or for that matter be concerned by) a sudden loss of water quality.

\subsubsection{Criterion 3: Individual's expectations of "quality water"}

A third aspect to consider is how individuals might relate to the nature of contamination itself. Results indicated in figure 2 reveal that individuals pay particular attention to the aesthetic aspects of water to determine its quality. In order to obtain these figures, individuals were first asked if "quality water" should have characteristics indicated in the title, and then asked how important this 


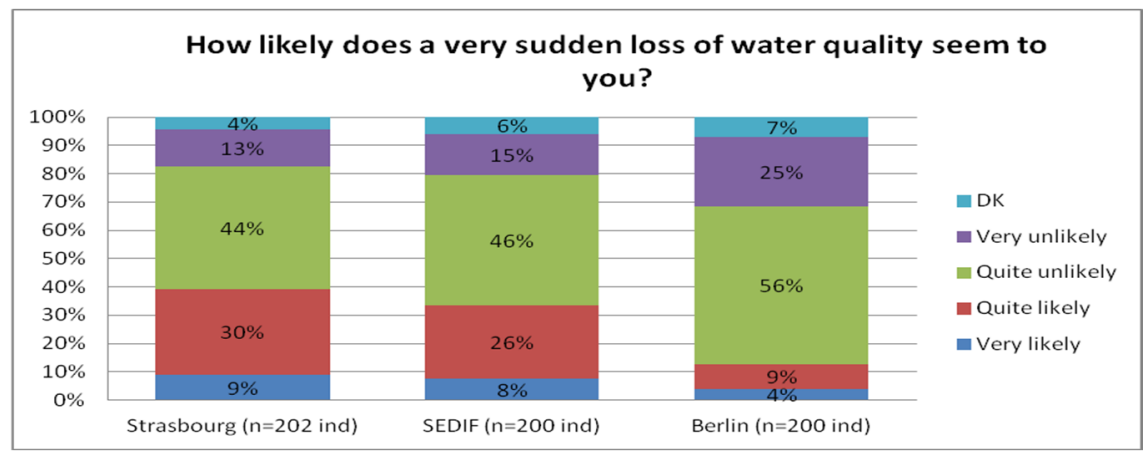

Figure 1: Distribution of belief of how likely a sudden loss of water quality is according to site. $(\mathrm{DK}=$ Does not know. SEDIF $=$ Paris-Ile de France).

absence or presence of the characteristic was. No significant differences were found between bottled and tap water drinkers in the characteristics presented in figure 2. Also, these results are concordant with contributions from other works which conclude similarly that individuals associate their satisfaction to water quality with water colour, flavour, and remembrance of water-related health problems [22].

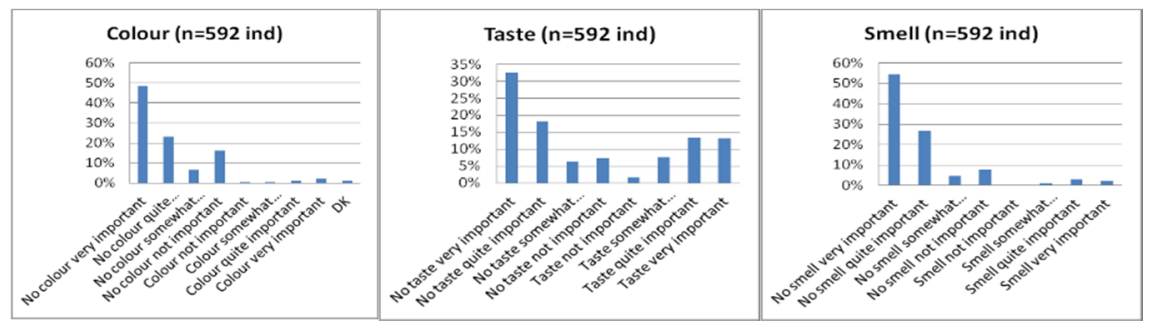

Figure 2: Preferences of individuals to determine quality water. ( $\mathrm{DK}=$ Does not know).

The subjective representation of water and its quality makes individuals potentially unreliable, especially if for example the contamination is odourless, tasteless and invisible. Should such a scenario arise, individuals would only be able to identify the contamination by linking the consumption of the water to the symptoms their exhibit. 


\subsection{Predisposition of individuals to communicate an identified sudden loss of water quality}

\subsubsection{Criterion 1: Anticipated reaction of individuals to a noticed sudden loss of water quality}

With respect to assessing the likeliness of communicating a noticed contamination, individuals were firstly asked to openly describe their reaction if they noticed a sudden loss of water quality. Based on a rigorous qualitative analysis of their open answers, we were able to categorise each individual into one of four groups:

1. Would intend to communicate a noticed problem to the water supplier, local authorities, emergency services, neighbours, friends or relatives.

2. Would intend to go searching for information on internet, television, radio without specifically mentioning the intention of communicating the noticed issue.

3. Would intend not to communicate the issue nor search for information on it. Would therefore not deal with the problem, or deal with it individually. Most individuals in this category stated their main action would be to exclusively switch or maintain using bottled water.

4. Undetermined: the statement does not give sufficient information to categorise the individual in the previous groups.

Results indicate that when asked to imagine a situation where water contamination is identified by the individual, a very significant part of them do not state that they would communicate or seek information concerning the contamination: 55\% in Strasbourg, 48\% in Paris-Ile de France and 41\% in Berlin. Respecting the previous order, only $27 \%, 27 \%$ and $40 \%$ mentioned behaviours categorised as communicating. More precisely, respectfully only $12 \%, 11 \%$ and $23 \%$ mentioned specifically contacting the water suppliers. Seeking information was respectively announced by $9 \%, 16 \%$ and $12 \%$. The remaining $9 \%, 10 \%$ and $7 \%$ was categorised as "undetermined".

As put forwards in section 4.2, our results do not constitute as such a prediction of individuals' behaviour if they noticed a contamination, as indeed the real-life behavioural outcome would also strongly be context-dependent. According to our results, potential communication levels are on the whole average to low, especially in the French sites. Cross-tabulation analysis of variables can offer us some explanations for this. To express correlations between answers, we used Cibois' Percentage of Maximum Deviancy (PMD) method [27]. It consists in qualifying with percentages how close or how far two variables are from maximum attraction (i.e. $100 \%$ positive correlation) or repulsion (i.e. 100\% negative correlation). Applying the PMD method to our data, individual's stated behaviour in case of water quality degradation was found to be mainly linked to two factors: belief of knowing who the water supplier is, and believing a sudden loss of water quality is unlikely (see Table 1). 
Table 1: Positive PMD of categories of measured level of knowledge of the water distribution system and answer categories from correlated variables.

\begin{tabular}{|c|c|c|c|}
\hline & \multicolumn{3}{|c|}{$\begin{array}{l}\text { Recoded categories to behaviour following noticed sudden loss of } \\
\text { water quality }\end{array}$} \\
\hline & $\begin{array}{l}\text { Would communicate } \\
\text { problem }(n=185 \text { ind })\end{array}$ & $\begin{array}{l}\text { Would seek information } \\
\qquad(n=73 \text { ind })\end{array}$ & $\begin{array}{l}\text { Would not communicate } \\
\text { problem }(n=285 \text { ind })\end{array}$ \\
\hline \multicolumn{4}{|c|}{$\begin{array}{l}\text { States knowing the name of the water supplier, regardless of correctness of } \\
\text { knowledge (Chi } p \text { value }=0.0377 \text { ) }\end{array}$} \\
\hline States knowing name of supplier ( $n=232$ ind) & $13 \%$ & & \\
\hline States not knowing the name of supplier ( $n=311$ ind) & & $7 \%$ & $10 \%$ \\
\hline \multicolumn{4}{|c|}{ Belief of likeliness of sudden loss of tap water quality $($ Chi $p$ value $=0.0019)$} \\
\hline Quality loss is very unlikely ( $\max =61,97$ ) & $24 \%$ & & \\
\hline Quality loss is unlikely $(\max =37,51)$ & & $36 \%$ & \\
\hline Quality loss is likely $(\max =55,12)$ & & & $7 \%$ \\
\hline Quality loss is very likely $(\max =17,58)$ & & & $43 \%$ \\
\hline Does not know how likely ( $n=32$ ind) & & & $41 \%$ \\
\hline
\end{tabular}

The first correlation observed can be explained quite simply: individuals who do not believe to know who is responsible for the water supply are less likely to know towards who they should turn if a contamination was noticed. Nevertheless, the nuance between believing to know who the water supplier is and actually knowing is very important. Indeed, other results have shown that a significant share of individuals who state knowing the name of the water supplier, actually give the wrong name afterwards (14\% state knowing the name and $10 \%$ give a wrong name in Strasbourg; 36\% and 8\% in Paris-Ile de France and $49 \%$ and $9 \%$ in Berlin). This means that even if individuals are willing to communicate a problem to water suppliers, a significant part of these would either not know who to turn to, or would get it wrong.

The second correlation is particularly noteworthy because it links negatively the levels of trust in the stability of water quality to the willingness to communicate in the event of noticed contamination. This finding confirms theory presented in section 2.1 which argues that trust fosters collaboration: in our case individuals with higher trust in water safety will be more likely to cooperate (by communicating) if they notice a threat $[2,4,13,28]$. So paradoxically, if we accept the assumption that less trustful individuals are more prepared to identify a contamination, this result suggests that very few individuals are predisposed to exhibit both key behaviours necessary for detection of water contaminations.

\subsubsection{Criterion 2: Individual's openness to participatory vigilance}

Results presented in figure 3 show that water users view favourably the development in the future of methods of vigilance which give a stronger role to water users. This result is particularly interesting because it makes visible the gap between the individuals' openness to participatory vigilance, and their potential behaviour which could be described as considerably more individualistic as seen in our results. 


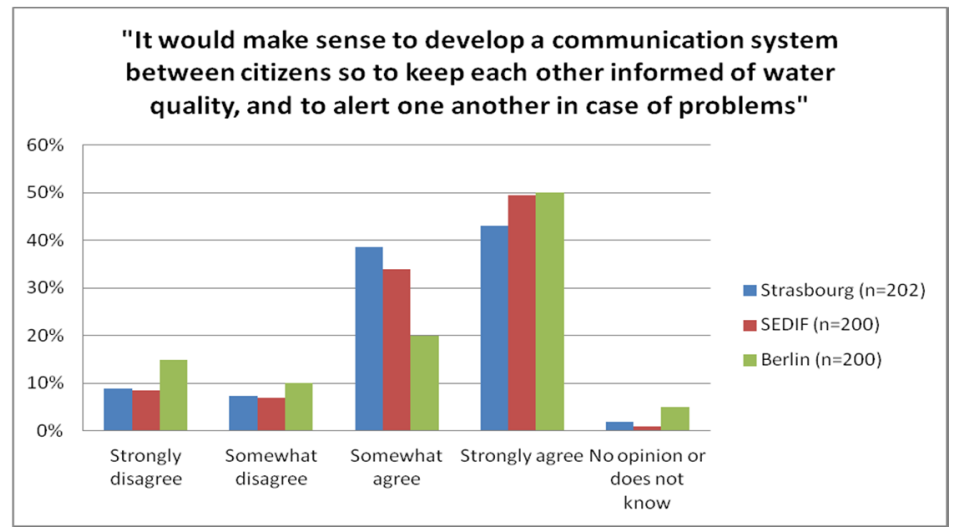

Figure 3: Openness to implicating water users into the vigilance of water quality. (SEDIF = Paris-Ile de France).

\subsection{Summary of results}

To summarise our main results, the findings suggest that if a widespread contamination were to occur, not only would it probably go unidentified by an important share of individuals, but even more importantly few of the individuals who notice the contamination would actually think, or know how, to communicate it. In sum, given the current configuration and in light of our data, water consumers appear to be predisposed to make poor "alarm raisers" should an unexpected water quality crisis occur.

We are therefore left to consider what might occur in the event of a particularly grave and undetectable contamination of water quality? Are water suppliers sufficiently equipped to identify water contaminations in time? What types of water vigilance strategies can be considered for the future? Could water suppliers channel a potential for involving water users in vigilance of water quality? We have in the next section considered three main directions for the future of water vigilance.

\section{Discussion and outcomes: how could the surveillance of water quality perception be improved in the future? Techno-vigilance and participatory vigilance}

\subsection{Techno-vigilance, or heavy reliance on technology}

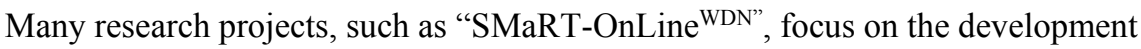
of technology which can help identify as rapidly as possible potential contaminations of the water distribution system. Such an approach has two main advantages: firstly, in optimal conditions, it enables the reliable identification of threats before they can cause damage to the individuals, and secondly it limits the 
potential for human errors. For these two main reasons, techno-vigilance appears to be the most relevant strategy in a short-term to mid-term perspective.

In a long-term perspective however, over-reliance on technology and a consequent under-reliance on individuals might be unproductive. Indeed firstly, as was stated in section 1, the complexity of urban water distribution systems is particularly great and continuously changing; even particularly well-developed technology might not be able to provide perfect surveillance at all times. Secondly, we argue that over-reliance on technology might encourage individuals to become increasingly less accustomed to taking helpful initiatives should technology fail or be bypassed.

\subsection{Participatory vigilance, or the active participation of individuals}

In light of the previous points, participatory vigilance might appear to be a relevant path to explore in order to optimise the surveillance of water distribution systems. Two reasons can be moved forward in favour of participatory vigilance. Firstly individuals occupy a strategic position in the water systems and can thus play a central role in water quality crisis management. Indeed they may serve a vital purpose by communicating key information to water suppliers, as well as warn other individuals nearby if necessary. Secondly, from a democratic standpoint, there appears to be an increasing demand for participation of citizens in domains which were originally considered exclusive to experts, such as City Services and Utilities.

In order to envisage individuals prepared for such participation, important changes would have to be considered in terms of the relation individuals currently have with experts and amongst each other. Better education would firstly be a key component as individuals would for instance need to be taught how to understand and identify a contamination of tap water and be instructed what actions to take in such a situation. Furthermore, trust relations would need to be improved since as we have seen in sections 2.1 and 4.3 these would be essential to harbour an optimal climate of cooperation.

However, the realism of putting participatory vigilance into practice might be questionable to some. It is perhaps too ambitious to expect a sufficient transformation of consumer-water supplier relations as previously described and to overcome the solidly established social, political and institutional norms which have long kept individuals separate from technical considerations in water management $[29,30]$.

\subsection{Informed vigilance, or the creation of water-knowledgeable individuals}

It becomes apparent that as technology develops to make our lives safer and simpler, it might also shift us away from learning how to rely on collective action to compensate for its limitations and possible failures. It also becomes apparent that full participatory vigilance would require too radical a change in the current management system to be applicable immediately, and would have its own limitations. A "third-way" should therefore be envisaged which could unfold a mid-term to long-term perspective. Individuals would not be expected to play a 
full-time role in the vigilance of water quality but they would nonetheless know how to articulate informed opinions about these issues and reflect on what appropriate actions should be taken during exceptional situations such as crises. As events such as water contamination event concern many people, the waterknowledgeable consumer would also be able to consider his/her situation collectively, rather than as an isolated individual.

Informed vigilance is in this respect the encouragement of individuals to stay informed, interested and able to shape a critical opinion of the technical dimension of water management. Our survey results suggest that individuals with higher knowledge of the water distribution system tend to show as a whole considerably higher trust in water quality, security and its stakeholders. This somewhat encouraging result suggests that one of the biggest obstacles to a positive participation of water users to water management could be overcome by promoting a public better understanding of it.

\section{Acknowledgements}

We wish to thank the Federal Ministry of Education and Research (BMBF) and the French National Research Agency (ANR) for the funding of our work inside the "SMaRT-OnLine ${ }^{\mathrm{WDN}}$ " collaborative project. All information about the project can be consulted on the project website: http://www.smart-onlinewdn.eu/.

\section{References}

[1] Beck, U. Risikogesellschaft, p. 521, 1986.

[2] Syme, G. J. \& Williams, K. D. The psychology of drinking water quality: an exploratory study. Water Resources Research, 29(12), pp. 4003-4010, 1993.

[3] Strang, V. Evaluating Water: Cultural Beliefs and Values about Water Quality, Use and Conservation, Oxford, 2001.

[4] Doria, M. F., Pidgeon, N. \& Hunter, P. R. Perception of tap water risks and quality: a structural equation model approach. Water Science and Technology, 52(8), pp. 143-149, 2005.

[5] Kleiner, Y., Nafi, A. \& Rajani,B. Planning renewal of water mains while considering deterioration, economies of scale and adjacent infrastructure, Water Science \& Technology: Water Supply, 10(6), pp. 897-906, 2010.

[6] Nafi, A. \& Kleiner, Y. Scheduling renewal of water pipes while considering adjacency of infrastructure works and economies of scale, Journal of Water Resources Planning and Management, 136(5), pp. 519-603, 2010.

[7] Beering, P.S. Threats on Tap: Understanding the Terrorist Threat to Water. Journal of Water Resources Planning and Management, 128 (3), p. 163, 2002.

[8] Salzman J. Drinking Water: a history, Overlook Duckworth, 2012.

[9] Kühnert C., Bernard T., Montalvo A.I. \& Nitsche R. Water Quality Supervision of Distribution Networks based on Machine Learning 
Algorithms and Operator Feedback. 16th International WDSA Conference, Bari, Italy, July 14-17, 2014.

[10] Ung, H., Piller, O., Deuerlein, J., Denis, G \& Montalvo, I. Lessons learned in solving the Contaminant Source identification in an online context. HIC Conference Informatics and the Environment: Data and Model Integration in a Heterogeneous Hydro World New York, USA August 17-21, 2014.

[11] Cvetkovich, G. The attribution of social trust (pp. 53-61). Social trust and the management of risk, eds G. Cvetkovich and R.E. Lofstedt, Earthscan, 1999.

[12] Lewis, J.D. \& A. Weigert. Trust as a social reality. Social Forces 63, pp. 967-985, 1985.

[13] Peters, R.G., V.T. Covello \& McCallum, D.B. The determinants of trust and credibility in environment risk communication: An empirical study, Risk Analysis, 17, pp. 43-54, 1997.

[14] Poortinga, W. \& Pidgeon, N.F. Exploring the dimensionality of trust in risk regulation. Risk Analysis, 23(5), pp. 961-972, 2003.

[15] Misztal, B. Trust in modern societies: the search for the bases of social order. Cambridge: Polity Press, 1996.

[16] Alesina, A. \& La Ferrara, E. Who trusts others? Journal of Public Economics 85, pp. 207-234, 2002.

[17] Baxter, J. \& Greenlaw, K. Explaining perceptions of a technological environmental hazard using comparative analysis. The Canadian GeoFigureer, 49, pp. 61-80, 2005.

[18] Bradbury, J.A., Branch, K.M. \& Focht, W. Trust and public participation in risk policy issues (pp. 117-127). Social trust and the management of risk, eds. G. Cvetkovich and R.E. Lofstedt, Earthscan, 1999.

[19] Cox, J. How to identify trust and reciprocity. Games and Economic Behaviour 46, pp. 260-281, 2004.

[20] Jeleva, M. \& Rossignol, S. Political decision of risk reduction: The role of trust. Public Choice, 139(1-2), pp. 83-104, 2009.

[21] Viklund, M. Trust and risk perception in Western Europe: A cross-national study. Risk Analysis, 23(4), pp. 727-738, 2003.

[22] Doria, M.F. Factors influencing public perception of drinking water quality. Water Policy, 12, pp. 1-19, 2010.

[23] Pidgeon, N. F., Kasperson, R. K. \& Slovic, P. The Social Amplification of Risk. Cambridge University Press, 2003.

[24] Selnes, F. 1998. Antecedents and consequences of trust and satisfaction in buyer-seller relationships. European Journal of Marketing, 38(3/4), pp. 305-322, 1998.

[25] Chateauraynaud, F. \& Torny, D. Mobilising around a risk: from alarm raisers to alarm carriers. Risques et Crises Alimentaires, eds. C. Lahellec, Paris: Tec \& Doc., 2005.

[26] Nickerson, R.S. Confirmation Bias: A Ubiquitous Phenomenon in Many Guises. Review of General Psychology, 2(2), pp. 175-220, 1998. 
[27] Cibois, P. Le PEM, pourcentage de l'écart maximum: un indice de liaison entre modalités d'un tableau de contingence, Bulletin de Méthodologie Sociologique, 40, pp. 43-63, 1993.

[28] Welch, M.R., Rivera, R.E.N., Conway, B.P., Yonkoski, J., Lupton, P.M. \& Giancola, R. Determinants and consequences of social trust. Sociological Inquiry, 75(4), pp. 453-473, 2005.

[29] Tsanga, M. The theory and practice of the local public service: the case of the drinking water supply, Ph. D. Thesis, Paris 10, 2003.

[30] Barraqué, B. Past and future sustainability of water policies in Europe. Natural Resources Forum, 27, pp. 200-211, 2003. 